\title{
Backward Conditioning: Mediation by the Context
}

\author{
Raymond C. Chang \\ State University of New York at Binghamton
}

\author{
Aaron P. Blaisdell \\ University of California, Los Angeles
}

\author{
Ralph R. Miller \\ State University of New York at Binghamton
}

\begin{abstract}
The information acquired in backward conditioning (i.e., outcome $\rightarrow$ cue) was assessed in 3 Pavlovian lick-suppression experiments with water-deprived rats as subjects. Experiment 1 confirmed previous research that few outcome $\rightarrow$ cue pairings made the cue into a conditioned excitor and additionally showed that massive posttraining extinction of the training context attenuated a backward-trained cue's excitatory value. Experiment 2 found that many outcome $\rightarrow$ cue pairings made the cue into a conditioned inhibitor and that the same context manipulation attenuated this inhibitory value. Experiment 3 confirmed the observations of Experiments 1 and 2 and demonstrated that these effects of context extinction were specific to backward-trained cues conditioned in the extinguished context. These results are interpreted in terms of cue $\rightarrow$ context and context $\rightarrow$ outcome associations.
\end{abstract}

In a backward conditioning procedure, the presentation of an outcome (usually an unconditioned stimulus [US]) precedes the onset of a cue (hereafter called a conditioned stimulus [CS; i.e., US $\rightarrow$ CS]). The content of learning after backward conditioning treatment is poorly understood at this time. In fact, most contemporary associative conditioning models say little or nothing about associations that could be formed in a backward conditioning situation (e.g., Mackintosh, 1975; Pearce \& Hall, 1980; Rescorla \& Wagner, 1972). These learning models implicitly assume that a CS-US associative link can be formed only when the CS has a predictive relationship to the US, which requires the CS to precede the US. Because the US is not predicted by a CS that follows it, these models anticipate that no association will develop during a backward conditioning procedure.

In contrast to these learning models, backward conditioning has been found empirically to affect behavioral control by the backward-trained CS. A typical observation is that a backward CS becomes an inhibitor (Maier, Rapaport, \& Wheatley, 1976; Moscovitch \& LoLordo, 1968; Plotkin \& Oakley, 1975; Siegel \& Domjan, 1971, 1974; see LoLordo \& Fairless, 1985, for a review), presumably because it signals an impending intertrial interval

Raymond C. Chang and Ralph R. Miller, Department of Psychology, State University of New York at Binghamton; Aaron P. Blaisdell, Department of Psychology, University of California, Los Angeles.

Support for this research was provided by National Institute of Mental Health Grant 33881. We thank Jeffrey Amundson, Francisco Arcediano, Martha Escobar, Steven Stout, and Dan Wheeler for commenting on an earlier version of this article. We also thank Daniel Burger, Amanda Ceraulo, Kenia Castellanos, and James Esposito for assistance in running the experiments.

Correspondence concerning this article should be addressed to Ralph R. Miller, Department of Psychology, State University of New York at Binghamton, Binghamton, New York 13902-6000. E-mail: rmiller@ binghamton.edu devoid of the US. However, these early studies overlooked the number of backward pairings as a potentially important variable. More recent studies have found that a large number of backward pairings tends to endow a CS with inhibitory value, whereas few pairings tend to make the CS an excitatory stimulus (Ayres, Haddad, \& Albert, 1987; Barnet \& Miller, 1996; Cole \& Miller, 1999; Heth, 1976; Heth \& Rescorla, 1973; Keith-Lucas \& Guttman, 1975; Spetch, Terlecki, Pinel, Wilkie, \& Treit, 1982; Tait \& Saladin, 1986). ${ }^{1}$ For example, Heth (1976), using a bar-press suppression preparation with rats, found that a backward CS was an excitor after 10 backward pairings but an inhibitor after 160 pairings. Similarly, our laboratory, using a conditioned licksuppression preparation with rats, has observed excitatory responding to a backward-trained CS after 4 or 16 backward pairings and inhibitory control after 96 backward pairings (Cole \& Miller, 1999). Moreover, Ayres et al. (1987) and Keith-Lucas and Guttman (1975) have shown that exposing rats to a single US $\rightarrow$ CS pairing was sufficient to endow the backward CS with excitatory potential (for a review, see Spetch, Wilkie, \& Pinel, 1981).

Although the number of trials appears to be critical in determining the nature of responding to a backward-trained CS, it is still unclear why this should be. LoLordo and Fairless (1985) and Williams, Dyck, and Tait (1988) proposed a cue-competition account, according to which the shift from excitation to inhibition presumably reflects the effectiveness of the context with increasing numbers of trials to compete with the backward-trained CS for controlling excitatory conditioned responding. The present experiments explored the role of context in excitatory and inhibitory

\footnotetext{
${ }^{1}$ Notably, the point of transition from excitation to inhibition with increasing numbers of trials appears to differ as a function of the response being monitored, presumably because different responses reflect associations to somewhat different US attributes (McNish, Betts, Brandon, \& Wagner, 1997; Tait \& Saladin, 1986).
} 
stimulus control produced by backward conditioning. In three conditioned lick-suppression experiments, we explored the mediating role of the training context with respect to the excitatory and inhibitory potentials of a backward-trained CS. Most of the present parameters were borrowed from Cole and Miller (1999). Although various theoretical accounts are examined, the present research is less about testing models than empirically illuminating the role of context in backward conditioning. Specifically in Experiments 1 and 2, we examined the possibility that one consequence of backward conditioning treatment is higher order conditioning, in which the conditioning context mediates either excitatory or inhibitory potential between the backward-trained CS and the US. This view was tested by providing posttraining context-alone exposures (i.e., context extinction) as well as manipulating the number of backward-training trials. If the conditioning context mediates the response potential of backward-trained CSs, posttraining context extinction should affect responding to the CSs (at least with some parameters; e.g., Rescorla, 1982). However, because context extinction took place only in the training context in Experiments 1 and 2, it was unclear whether the decrements of excitation and inhibition observed in Experiments 1 and 2 were context specific. Experiment 3 addressed this question. Thus, Experiments 1, 2, and 3, respectively, were designed to explore (a) potential positive mediation by the training context (i.e., a positive correlation between the response potential of the target CS and the associative status of the context that followed it, akin to second-order conditioning), (b) potential negative mediation by the context (i.e., a negative correlation between the response potential of the target $\mathrm{CS}$ and the associative status of the context, akin to Pavlovian conditioned inhibition), and (c) the context specificity of any observed effects in Experiments 1 and 2.

\section{Experiment 1: Context Effects on Backward Excitation}

In light of previous experiments (e.g., Moscovitch \& LoLordo, 1968; Williams et al., 1988), the physical context in which conditioning occurs is one possible stimulus that may mediate both the excitatory and inhibitory potentials of a backward-trained CS. For instance, Moscovitch and LoLordo (1968) found that a backward CS trained with a consistent intertrial interval was a more effective conditioned inhibitor than a backward CS trained with a random intertrial interval of equal average value. They suggested that this occurred because a consistently large temporal distance between termination of the backward-trained CS and onset of the next scheduled US (footshock in their situation) permitted the CS to predict a safe period in the conditioning context that was devoid of the US. Consistent with this view, Dostalek and Krasa (1972, 1973) found no inhibition to develop when the intervals between successive backward pairings were so random that no safe interval in the conditioning context existed after each pairing. With a sufficiently consistent intertrial interval, prior to subjects learning that there is a safe period following each trial, the context should be uniformly excitatory and hence potentially able to act as a first-order excitor for the second-order excitatory conditioning of a CS. That a conditioning context can mediate excitation between a CS and a US was clearly demonstrated by Marlin (1983; however, she used a conventional two-phase second-order conditioning procedure [context $\rightarrow$ US and CS $\rightarrow$ context] in contrast to the single-trial-type procedure [context $\rightarrow \mathrm{US} \rightarrow \mathrm{CS} \rightarrow$ context] of the present research). Thus, in backward conditioning, an excitatory conditioning context may act as either an excitatory or inhibitory mediator, depending on the degree of training (see General Discussion for elaboration).

As noted by Cole and Miller (1999), a potential common denominator across conditioned excitation and inhibition produced by backward conditioning is that in both cases the CS may come to predict what immediately follows it. However, excitation and inhibition produced by backward conditioning may differ from each other in terms of the extent that the subject has learned to segment the context into different temporal components as a function of time since the last CS presentation. Here we suggest that early in training (i.e., few backward trials) the subject has not yet learned the regularity of the intertrial intervals, making the entirety of the context (i.e., global context) indistinguishably excitatory. But with more backward trials with a consistent minimum intertrial interval, the subject learns that there is a short safe (i.e., shock-free) period that follows the CS (i.e., local context). Local context as used here is not based on mere onset or termination of events but rather is based on temporal anticipation of outcomes immediately following the target CS (e.g., Gallistel \& Gibbon, 2000; Gibbon, 1977; Gibbon \& Balsam, 1981).

In this framework, with few backward pairings, the small number of trials does not permit subjects to estimate the temporal separation of the unsignaled USs, thereby making the global context excitatory. Thus, at test following few backward-training trials, the CS activates the representation of the global context inducing fear through a CS $\rightarrow$ global context $\rightarrow$ US sequence. In other words, the context immediately following the CS may mediate excitation between the CS and US because the global context has been made excitatory by the unsignaled USs. In this view, the context is excitatory throughout the session including immediately after the CS. Excitatory backward conditioning is a consequence of the subject not differentiating the various temporal components of the context throughout the training session.

In contrast, with many backward trials, the temporally local context immediately following the CS now constitutes a safe period relative to other parts of the intertrial interval in the context. That is, as a result of many training trials, the CS may come to predict the onset of the safe portion of the intertrial interval immediately following CS termination (CS $\rightarrow$ post-CS local context $\rightarrow$ no US). At the time of testing, the backward-trained CS now activates a representation of the local training context that immediately followed it in training. The inhibitory properties of such a CS reflect anticipation of a safe period. Thus, backward conditioned inhibition is a result of the subject's coming to learn through further backward-training trials that the local context immediately following each CS presentation is safe, which is consistent with Moscovitch and LoLordo's (1968) and Dostalek and Krasa's $(1972,1973)$ results. In summary, to the extent that the CS is followed by the excitatory context during a few backward pairings, the CS may become a second-order excitatory conditioned stimulus. But with a large number of backward pairings, the subject may encode the consistent occurrence of a US-free period in the local context that immediately follows each CS, and the CS may become inhibitory because of its signaling this safety period (Denny, 1971). Because the CS now predicts the shock-free local context (CS $\rightarrow$ post-CS local context $\rightarrow$ no US), which is discriminated from the subsequent context that is associated with shock, 
the backward-trained inhibition procedure resembles the procedure for inducing conditioned inhibition through explicitly unpaired trials of the CS and US.

The central hypothesis here for both few and many backward pairings is that the CS's control of behavior depends on the events that immediately follow the CS (i.e., forward conditioning). This is not to deny the possibility that subjects also learn backward associations (US $\leftarrow \mathrm{CS}$ ), but such associations by themselves likely do not support conditioned excitatory responding to a CS unless a predictive relationship is independently created to assess them (e.g., Barnet \& Miller, 1996; Cole \& Miller, 1999; Miller \& Barnet, 1993; Savastano \& Miller, 1998; but see Williams \& Hurlburt, 2000). As the training context is the only cue present immediately prior to the US during training, it is reasonable to expect that the context plays a large role in modulating excitatory conditioned responding to a backward-trained CS. However, empirical support for this role of the conditioning context in backward conditioning is still lacking.

The mediating role of the training context potentially can sometimes be inferred from the consequences of posttraining devaluation of its excitatory value. That is, in some instances posttraining extinction of the mediating cue reduces responding to a secondorder CS (e.g., Rescorla, 1982), whereas in select other instances this effect is not observed (e.g., Rizley \& Rescorla, 1972). Thus, the observation of diminished responding documents mediation, whereas the absence of such a diminished responding is not strong evidence against mediation. In Experiment 1, after 4 or 96 backward US $\rightarrow$ CS pairings, the excitatory potential of the global training context was extinguished by exposing subjects to it in the absence of programmed events. According to the present context mediation hypothesis, devaluing the context's association to the footshock US after 4 backward US $\rightarrow$ CS pairings might well attenuate the excitatory potential of the context that immediately follows the CS, thereby reducing mediated excitatory responding to that CS. In contrast, devaluing the global context's association to the US after 96 backward US $\rightarrow$ CS pairings was not expected to have any attenuating effect on the CS's manifest excitatory potential, because the CS after so many training trials was not expected to be excitatory (see Experiment 2 for an inhibitory test of the consequences of this manipulation). In Experiment 1 (with $\mathrm{X}$ representing the target $\mathrm{CS}$ ), we assessed whether massive devaluation of the context-US and CS X-context associations would attenuate the degree to which a backward-trained CS elicits excitatory conditioned responding.

The design of Experiment 1 is depicted in Table 1. We exposed some rats to either 4 or 96 US $\rightarrow$ X pairings in Phase 1. In Phase 2, subjects from each Phase 1 condition received different durations of exposure to the training context. If the excitatory context functions as a conditioned mediator of excitation with few backward pairings and as the basis for conditioned inhibition with many backward pairings, both effects should be attenuated by massive posttraining extinction of the global context. In Experiment 1, we administered a test for excitation, and in Experiment 2, we performed a parallel study that ended with a test for inhibition.

\section{Subjects}

\section{Method}

Twenty-four male (273-391 g) and 24 female (194-261 g) experimentally naive Sprague-Dawley descended rats bred in our colony served as
Table 1

Design Summary for Experiment 1: Excitor Test

\begin{tabular}{lcccc}
\hline \multicolumn{1}{c}{ Group } & Phase $1_{\mathrm{A}}$ & Phase $2_{\mathrm{A}}$ & Phase $3_{\mathrm{A}}$ & $\begin{array}{c}\text { Expected response } \\
\text { to CS } \mathrm{X}_{\mathrm{B}}\end{array}$ \\
\hline Many-long & $96 \mathrm{US} \rightarrow \mathrm{X}$ & $(600 \mathrm{~min})$ & $8 \mathrm{~T} \rightarrow \mathrm{US}$ & $\mathrm{cr}$ \\
Many-short & $96 \mathrm{US} \rightarrow \mathrm{X}$ & $(20 \mathrm{~min})$ & $8 \mathrm{~T} \rightarrow \mathrm{US}$ & $\mathrm{cr}$ \\
Few-long & $4 \mathrm{US} \rightarrow \mathrm{X}$ & $(600 \mathrm{~min})$ & $8 \mathrm{~T} \rightarrow \mathrm{US}$ & $\mathrm{cr}$ \\
Few-short & $4 \mathrm{US} \rightarrow \mathrm{X}$ & $(20 \mathrm{~min})$ & $8 \mathrm{~T} \rightarrow \mathrm{US}$ & $\mathrm{CR}$ \\
\hline
\end{tabular}

Note. Long and short denote the duration of Phase 2 context exposure (600 min or $20 \mathrm{~min}$ ). Subscripts $A$ and $B$ indicate train context and test context, respectively. Numbers next to the pairings $(96,8$, and 4$)$ indicate number of trials. $C R$ (conditioned responding) denotes strong responding, and $\mathrm{cr}$ denotes weak responding, as anticipated by the context mediation hypothesis. $\mathrm{X}=$ click train; $\mathrm{T}=$ tone; $\mathrm{US}=$ unconditioned stimulus (1-mA, 1-s footshock); many = 96 Phase 1 backward US-CS pairings; few $=4$ Phase 1 backward US-CS pairings; $\mathrm{CS}=$ condition stimulus; $\rightarrow$ $=$ followed by; ()$=$ context extinction.

subjects. Subjects were individually housed in wire-mesh cages in a vivarium maintained on a 16-hr light:8-hr dark cycle. Experimental manipulations occurred approximately midway through the light phase. A progressive water-deprivation schedule was imposed over the week prior to the beginning of the experiment, until water availability was limited to $20 \mathrm{~min}$ per day. All animals were handled three times per week for $30 \mathrm{~s}$, from weaning to the initiation of the study. Subjects were randomly assigned to one of four groups ( $n \mathrm{~s}=12$ ), counterbalanced for sex: many-long, many-short, few-long, and few-short (with few and many referring to the number of backward pairings during training, and long and short referring to the duration of the posttraining sessions during which the training context was extinguished).

\section{Apparatus}

Twelve identical experimental chambers, each measuring $30 \times 25 \times 32$ $\mathrm{cm}(1 \times \mathrm{w} \times \mathrm{h})$, were used. The walls of each chamber were made of Plexiglas, and the floor was constructed of $0.5-\mathrm{cm}$ diameter stainless steel rods, spaced $2 \mathrm{~cm}$ center to center, and connected by NE-2 neon bulbs, which allowed a $1.0-\mathrm{mA}$ constant-current footshock to be delivered by means of a high-voltage AC circuit in series with a 1.0-M $\Omega$ resistor. Each chamber was housed in its own environmental isolation chest, which was dimly illuminated by a houselight (\#1820 incandescent bulb) mounted on the ceiling of the experimental chamber. Each chamber could be equipped with a water-filled lick tube (opening $=0.3 \mathrm{~cm}$ in diameter) that extended $1 \mathrm{~cm}$ from the rear of a cylindrical niche, $4.5 \mathrm{~cm}$ in diameter, that was left-right centered on one narrow wall, with its axis perpendicular to the wall and positioned $4 \mathrm{~cm}$ above the grid floor. An infrared photobeam was projected horizontally across the niche, $1 \mathrm{~cm}$ in front of the lick tube. In order to drink from the tube when it was present, subjects had to insert their heads into the niche, thereby breaking the horizontal infrared photobeam. Thus, the amount of time the photobeam was disrupted could be monitored; this served as our dependent variable. Two widely separated $45-\Omega$ speakers were mounted on the back and side walls of each environmental chest. Each speaker could deliver a high-frequency complex tone ( 3000 and $3200 \mathrm{~Hz}$ ) or a click train stimulus (6 per second), both $8 \mathrm{~dB}$ (A scale) above background. The click train always served as the target CS $(\mathrm{X})$; the tone always served as a transfer excitor (Stimulus T), which was required for the summation test in Experiment 2 and was included in Experiment 1 only for consistency across the two experiments. All CSs were $30 \mathrm{~s}$ in duration. The US was a 1-s, 1-mA footshock. A ventilation fan in each enclosure provided a constant 76- $\mathrm{dB}$ (A scale) background noise.

Two different contexts (train and test) were constructed out of these chambers. The apparatus as just described without the lick tube present 
constituted the train context, which was the site of all training (Phases 1 and 2). For the test context, the site of testing, a Plexiglas sheet was placed on top of the grid floor, the houselight was off throughout the session, the lick tubes were installed, and a background odor was present (the result of two drops of methyl salicylate, a mint odor, on the top surface of a wooden cube positioned inside the sound-attenuating environmental isolation chest but outside the experimental chamber). For each subject, the specific physical chamber used for training differed from that used for testing. The purpose of our using different contexts for training and testing was to avoid confounds that might be introduced by our testing in the training context in which different groups had received unequal amounts of context extinction or different numbers of footshocks. That is, 96 backward pairings (many condition) during Phase 1 and little context extinction (short condition) during Phase 2 would have made the train context more excitatory than would 4 backward pairings (few condition) during Phase 1 and extensive context extinction (long condition) during Phase 2. If testing had taken place in the same training context, test contexts with different excitatory values might have differentially affected conditioned responding to the CS presented at test. By testing the subjects in a neutral context, we were able to minimize this potential confound.

\section{Procedure}

The design and group names of the experiment are depicted in Table 1. Acclimation. Animals in the many-long and many-short groups were acclimated to context test for $30 \mathrm{~min}$ on Day 1 . Animals in the few-long and few-short groups were acclimated to the test context for 30 min on Day 12 and received handling comparable with the many-long and many-short groups on Days 1-11. The animals had free access to the water-filled tubes during this session.

Backward conditioning (Phase 1). On Day 13 in the train context, the few-long and few-short groups received four backward US -X pairings in a 20 -min session. During the first $5 \mathrm{~min}$ and last $4.5 \mathrm{~min}$ of the session, no stimuli were programmed to occur. Trial presentations began $5,8,11$, and $15 \mathrm{~min}$ into the session, with a mean intertrial interval of $169 \mathrm{~s}$ (the intertrial interval is here defined as the time between the termination of a backward-trained CS and the onset of the next US). For the many-long and many-short groups, the training regimen was administered over 12 days (Days 2-13) in the train context, with 8 trials of US $\rightarrow$ X pairings per daily 30 -min session. The mean intertrial interval was $124 \mathrm{~s}$, and the first 6 and the last $5.5 \mathrm{~min}$ of the session contained no programmed events. To assure that the subjects did not learn any precise trial spacing, we used two training schedules. The trial onset time for the first schedule was $6,8,10$, $13,15,18,21$, and $24 \mathrm{~min}$ into the session, and the trial onset time for the second schedule was $6,9,11,14,17,19,22$, and 24 min into the session.

Context extinction (Phase 2). On Days 14-17, all groups received exposure to the train context. The rationale for this phase was to devalue the context-US association (and perhaps the CS-context association), which the subjects presumably acquired during the backward conditioning treatment of Phase 1. Animals in the many-long and few-long groups were placed in the train context for $150 \mathrm{~min}$ each day without any nominal events being programmed to occur, whereas the many-short and few-short groups received $5 \mathrm{~min}$ of context-only exposure during their daily sessions (thereby providing equivalent handling with minimal context extinction).

Transfer excitor training (Phase 3). On Days 18 and 19, all groups received 4 daily presentations of forward $\mathrm{T}$-US pairings in the train context. Session length was $16 \mathrm{~min}$. No nominal stimuli were programmed to occur in the first $4 \mathrm{~min}$ and the last $3.75 \mathrm{~min}$ of the session. The intertrial intervals for this phase were 105,120, and $150 \mathrm{~s}$ (mean intertrial interval $=$ $125 \mathrm{~s}$ ). The purpose of this phase was to provide experience equivalent to Experiment 2, which used CS $\mathrm{T}$ as a transfer excitor in an inhibitory summation test.
Reacclimation. On Days 20 and 21, all of the animals were reacclimated to the test context with the lick tubes in place. Session duration was $30 \mathrm{~min}$

Testing of X. On Day 22, all animals were tested on CS X in the test context with the lick tubes present. CS X was presented on completion of an initial 5 cumulative seconds of drinking. In this and the subsequent experiments, consistent with long-standing practice in our laboratory, subjects failing to complete the first 5 cumulative seconds of drinking (pre-CS scores) within $60 \mathrm{~s}$ of placement in the test context were scheduled to be eliminated from the study for exhibiting unusually great fear of the test context. Specifically, 1 animal in the few-short group was excluded because of its failure to complete its first 5 cumulative seconds of licking within $60 \mathrm{~s}$ of placement in the test context. Additionally, 1 animal in the few-long group died prior to completion of the experiment. Times to complete 5 cumulative seconds of licking prior to presentation of CS X and during the presence of CS X were converted into $\log _{10}$ time to improve the normality of the distribution of scores within groups. A 10-min ceiling was imposed on the suppression scores

\section{Results and Discussion}

A $2 \times 2$ analysis of variance (ANOVA), with number of Phase 1 trials and duration of Phase 2 context exposure as factors, was conducted on the pre-CS scores. No statistically significant difference among groups was detected, $F_{\mathrm{s}}(1,42) \leq 3.00, p \mathrm{~s}>.05$. The CS scores were analyzed using an analysis of covariate (ANCOVA), with pre-CS scores as the covariate. A $2 \times 2$ ANCOVA, with trial number and duration of Phase 2 context exposure as factors, on the drinking scores during the presentation of CS X yielded a main effect of trials, $F(1,41)=54.23$, $M S E=0.12, p<.001$, and duration, $F(1,41)=11.32$, $M S E=0.12, p<.005$, as well as a Trials $\times$ Duration interaction, $F(1,41)=8.67, M S E=0.12, p<.01$.

The ANCOVA-adjusted mean licking scores (log time) during the presence of CS X are shown in Figure 1. Planned comparisons were performed to illuminate these effects using the overall error term from the ANCOVA on the CS scores. These contrasts re-

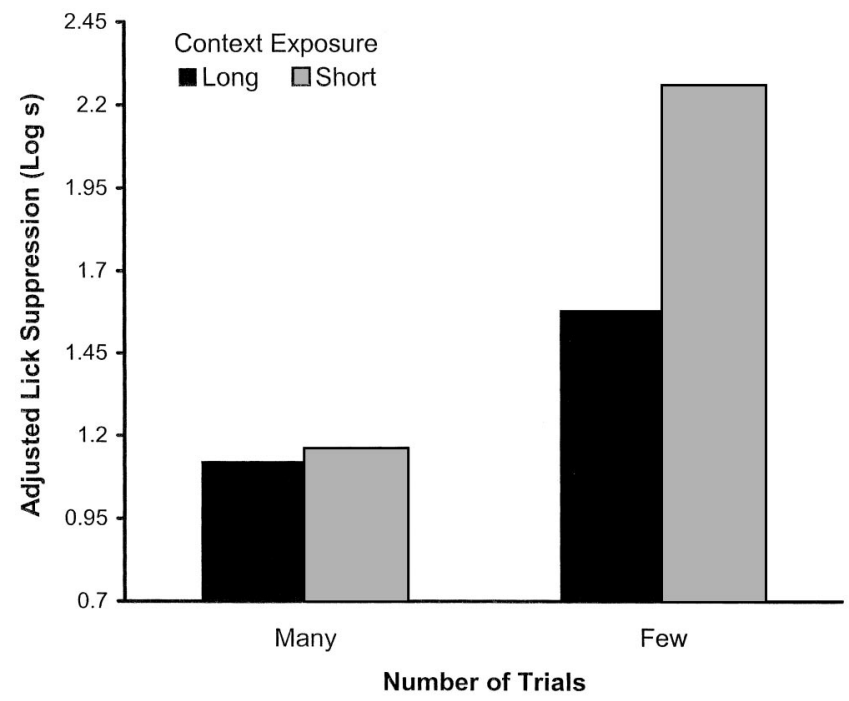

Figure 1. Excitation test in Experiment 1: adjusted mean drinking suppression during the presentation of CS X. The adjustment was based on the pre-CS drinking scores. $\mathrm{CS}=$ conditioned stimulus 
vealed that we had replicated the previous observations of Cole and Miller (1999) and Heth (1976) that animals exposed to few backward pairings (US $\rightarrow \mathrm{X}$ ) suppressed more than animals exposed to extensive numbers of backward pairings, $F(1$, $41)=50.03, p<.001$ (many - short vs. few - short groups), and $F(1,41)=10.21, p<.005$ (many-long vs. few-long groups). That is, a CS trained with few (4) backward pairings proved more excitatory than one trained with many (96) backward pairings. More important, massive posttraining extinction of the context attenuated the level of excitatory responding to CS X in groups that received 4 backward pairings in Phase 1 (few-long vs. fewshort groups), $F(1,41)=18.51, p<.001$, but had little or no effect on the level of responding to CS X in groups exposed to 96 backward pairings (many-long vs. many-short groups), $F(1$, $41)<1.0$. Notably, preliminary studies with no CS-US pairings (forward or backward) but otherwise using the same procedure yielded mean suppression to the CS of $0.8-1.0 \log \mathrm{s}$. Thus, the many-long and many-short groups were near but not at baseline (see Figure 1).

One might wonder why the T-US pairings of Phase 3 did not counter the extinction of the context that occurred during Phase 2. We expected that any such effect would not be large because the signaling of the USs by CS T should have at least partially overshadowed any possible enhancement of the context-US association as a result of the T-US pairings. The observation of differences in behavioral control by CS X as a function of amount of context extinction in Phase 2 supports this assumption. Moreover, Experiment 3 directly demonstrates that the present results were not appreciably influenced by this possibility.

The present data indicate that context extinction has little or no effect on the (low) excitatory potential of the extensively trained backward CS X, which possibly reflects a floor effect. That is, there was an equally low level of conditioned responding to CS X seen in the many-long and many-short groups. More interestingly, the data suggest that in the few condition, the training context served as a mediator of excitatory responding. This is supported by the observation that massive extinction of the global context-US association (and perhaps the CS-global context association) in animals that only received 4 backward pairings in Phase 1 (few-long) exhibited attenuated excitatory responding to the backward-trained CS $\mathrm{X}$ relative to its comparison group (few-short). The implication is that in the few condition, the context functioned as a positive mediator of conditioned excitation for CS X (e.g., Holland \& Forbes, 1982; also see the temporal coding hypothesis as outlined by Savastano \& Miller, 1998). By positive mediator, we mean that changes in responding to the target CS were positively correlated with changes in the associative status of the mediator. Seemingly, during Phase 1 training in the few condition, CS X came to predict the presence of the context (CS X $\rightarrow$ train context), and the train context came to predict the US (train context $\rightarrow$ US). In this framework, the excitatory response potential of CS X was a result of the CS X $\rightarrow$ train context $\rightarrow$ US associative chain, and in turn, the associative chain itself was a consequence of integration of the CS X $\rightarrow$ train context and train context $\rightarrow$ US associations through the common element of the two associations (the train context). The absence of excitatory responding observed in the many condition may have been due to the additional pairings providing the subject with the opportunity to learn that there was a predictable safe period following each CS.

One alternative to the context mediation hypothesis as an account of why with few pairings a backward-trained CS becomes an excitor is that the CS may have become directly (forward) associated with the next US. The relatively short intertrial intervals used in training would favor the formation of such a forward association. But the present short intertrial intervals are also compatible with the context mediation hypothesis because a short intertrial interval should have made the context more excitatory than a long intertrial interval. The critical observation for differentiating between these two views is that posttraining context extinction decreased the excitatory potential of the target CS. This is consistent with the context mediation hypothesis but is inexplicable in terms of direct CS-US associations.

\section{Experiment 2: Context Effects on Backward Inhibition}

Experiment 1 assessed the consequences of posttraining context extinction on excitation resulting from backward training. Thus, the nature of the test trials precluded any determination of whether context extinction could influence the inhibitory response potential of an extensively trained backward CS. Tests of simple excitation (as opposed to summation or retardation tests) are not sensitive to inhibition. However, the previously discussed context mediation hypothesis assumes that extensive backward training causes a CS to become a second-order conditioned inhibitor on the basis of its predicting the local context, which is assumed to be a first-order inhibitor because it itself is shock free but associated to the excitatory global context. If this is correct, extinction of the (global) context should attenuate the inhibitory value of the local context and consequently the inhibitory value of the backwardtrained CS, just as posttraining extinction of the training excitor is typically known to do in the case of conditioned inhibition produced through other procedures (e.g., Best, Dunn, Batson, Meachum, \& Nash, 1985; Hallam, Matzel, Sloat, \& Miller, 1990; Lysle \& Fowler, 1985, in Pavlovian conditioned inhibition; Miller, Hallam, Hong, \& Dufore, 1991, in differential inhibition; and Kasprow, Schachtman, \& Miller, 1987; Schachtman, Brown, Gordon, Catterson, \& Miller, 1987, in negative contingency conditioned inhibition).

Thus, the purpose of Experiment 2 was to investigate the effect of massive posttraining extinction of the global training context on the inhibitory potential of a backward-trained conditioned inhibitor. The procedure was identical to Experiment 1, except for the following: (a) We did not include groups with few backward pairings of the CS because such a CS lacks initial inhibitory control of behavior (Cole \& Miller, 1999; Heth, 1976); (b) we used a summation test instead of a test for excitation; (c) we added control groups that were tested with only the transfer excitor from the summation test; and (d) the test ceiling was increased from 10 min to $15 \mathrm{~min}$. The last change was made because we anticipated that the summation test of the present experiment relative to the excitor test of Experiment 1 would raise suppression scores, thereby making a 10-min ceiling insufficiently sensitive. We used a summation test instead of a retardation test in order to minimize confounding by any potential latent inhibition effects; that is, the large number of backward pairings might have produced retarda- 
tion through latent inhibition in addition to or instead of through conditioned inhibition (see Table 2).

\section{Method}

\section{Subjects and Apparatus}

Twenty-four male (209-383 g) and 24 female (186-267 g) experimentally naive Sprague-Dawley descended rats bred in our colony served as subjects. Housing and water-deprivation schedules were identical to Experiment 1 . The subjects were randomly assigned to one of four groups counterbalanced for sex $(n \mathrm{~s}=12)$ : long-TX, short-TX, long-T, and short $-\mathrm{T}$. The apparatus and stimuli were the same as those used in Experiment 1.

\section{Procedure}

Table 2 summarizes the critical aspects of the procedure for the different groups. The procedure was identical to Experiment 1 unless stated otherwise.

Acclimation and backward conditioning (Phase 1). All animals were acclimated to the test context for $30 \mathrm{~min}$ on Day 1, as in Experiment 1. On Days 2-13, all groups underwent Phase 1 backward conditioning in the train context identical to the many-long and many-short groups of Experiment 1.

Context extinction (Phase 2). On Days 14-17, all groups were exposed to the train context. As in Experiment 1, these daily sessions were $5 \mathrm{~min}$ in duration for the short condition and $150 \mathrm{~min}$ in duration for the long condition.

Transfer excitor training (Phase 3). On Days 18 and 19, all animals received four daily forward pairings of CS T with the US $(\mathrm{T} \rightarrow \mathrm{US})$ in the train context identical to those in Experiment 1.

Reacclimation and testing. On Days 20 and 21, all animals were reacclimated to the test context, as in Experiment 1. On Day 22, animals in the long-TX and short-TX groups were tested with a simultaneous compound of the tone and click (TX). The long-T and short-T groups were tested with the tonal transfer stimulus alone (T). All test CSs were presented on completion of 5 cumulative seconds of drinking so that all subjects were drinking at CS onset. A 15-min ceiling was imposed on all suppression scores. One animal in the long-T group was excluded from all analyses because of its failure to complete its first 5 cumulative seconds of licking (i.e., prior to CS onset) within $1 \mathrm{~min}$ of placement in the test context on Day 22. The drinking scores (prior to and during the CS presentation) were subjected to a $\log _{10}$ transformation.

Table 2

Design Summary for Experiment 2: Summation Test

\begin{tabular}{lccccc}
\hline Group & Phase $1_{\mathrm{A}}$ & Phase $2_{\mathrm{A}}$ & Phase $3_{\mathrm{A}}$ & Test $_{\mathrm{CS}} \mathrm{B}_{\mathrm{B}}$ & $\begin{array}{c}\text { Expected } \\
\text { response } \\
\text { to test CS }\end{array}$ \\
\hline Long-TX & $96 \mathrm{US} \rightarrow \mathrm{X}$ & $(600 \mathrm{~min})$ & $8 \mathrm{~T} \rightarrow \mathrm{US}$ & $\mathrm{TX}$ & $\mathrm{CR}$ \\
Short-TX & $96 \mathrm{US} \rightarrow \mathrm{X}$ & $(20 \mathrm{~min})$ & $8 \mathrm{~T} \rightarrow \mathrm{US}$ & $\mathrm{TX}$ & $\mathrm{cr}$ \\
Long-T & $96 \mathrm{US} \rightarrow \mathrm{X}$ & $(600 \mathrm{~min})$ & $8 \mathrm{~T} \rightarrow \mathrm{US}$ & $\mathrm{T}$ & $\mathrm{CR}$ \\
Short-T & $96 \mathrm{US} \rightarrow \mathrm{X}$ & $(20 \mathrm{~min})$ & $8 \mathrm{~T} \rightarrow \mathrm{US}$ & $\mathrm{T}$ & $\mathrm{CR}$ \\
\hline
\end{tabular}

Note. Long and short denote the duration of Phase 2 context exposure (600 min or $20 \mathrm{~min}$ ). Subscripts $A$ and $B$ indicate train context and test context, respectively. Numbers next to the pairings (96 and 8) indicate number of trials. $C R$ (conditioned responding) denotes strong responding, and $c r$ denotes weak responding, as anticipated by the context mediation hypothesis. $\mathrm{X}=$ click train; $\mathrm{T}=$ tone; $\mathrm{US}=$ unconditioned stimulus (1-mA, 1-s footshock); TX = tone-click compound; CS = conditioned stimulus; $\rightarrow=$ followed by; ( ) = context extinction.

\section{Results and Discussion}

A $2 \times 2$ ANOVA was performed on the pre-CS times, with the duration of context exposure (long vs. short) of Phase 2 and the test CSs (TX vs. T) as factors. No statistically significant differences in pre-CS scores were detected among the groups, $F \mathrm{~s}(1,43) \leq 1.50$, $p s \geq .53$. This indicates that all groups had similar baselines of drinking prior to the presentation of the test CS. The transformed suppression scores recorded during presentation of the test CS were then analyzed with a $2 \times 2$ ANCOVA, with pre-CS time as the covariate. A main effect of duration (long vs. short) was observed, $F(1,42)=7.11, M S E=0.27, p<.05$, as was a marginally significant main effect of test CS (TX vs. T), $F(1$, $42)=3.47, M S E=0.27, p=.07$. More important, as predicted by the context mediation account, a Duration $\times$ Test CS interaction was detected, $F(1,42)=4.14, M S E=0.27, p<.05$.

The adjusted mean suppression scores are depicted in Figure 2. To understand the patterns of the main effects and interaction, we performed several planned comparisons using the overall error term of the ANCOVA on the CS scores. Without extensive context extinction, CS X had strong inhibitory potential, $F(1,42)=7.67$, $p<.005$ (short-TX vs. short $-\mathrm{T}$ groups). In contrast, with extensive context extinction, CS $\mathrm{X}$ failed to attenuate the excitatory response to the transfer excitor $(\mathrm{T})$ tone in the long-TX group relative to the long-T group, $F(1,42)<1.0$ (long-TX vs. long-T groups). Moreover, massive posttraining context extinction attenuated the inhibitory potential of the backward-trained CS X relative to minimal posttraining context extinction, $F(1,42)=11.03$, $p<.05$ (long-TX vs. short-TX groups).

On the basis of the results of Experiment 2, massive posttraining context extinction appears to attenuate the inhibitory value of the backward CS (X), as assessed with a summation test. Animals that received little posttraining context exposure suppressed less to the tone-click compound than to the transfer excitor (tone) alone. In contrast, suppression in the long-TX and long-T groups was similarly high. This indicates that with massive posttraining extinction of the train context, the backward CS did not appreciably inhibit suppression to the transfer excitor. The present results are consistent with the sometimes observed attenuating effects on Pavlovian conditioned inhibition of massively extinguishing the training excitor (e.g., Hallam et al., 1990).

One possible criticism of the design of Experiment 2 is the possibility of stimulus generalization decrement (see Papini \& Bitterman, 1993). That is, the lower suppression to compound CS TX than CS T after training with CS T alone (short-TX group vs. short $-\mathrm{T}$ group) could have originated in generalization decrement between T and TX. However, a similar degree of stimulus generalization decrement would be expected in the long condition, and this loss of suppression was not observed. Thus, the stimulus generalization decrement explanation fails to fully account for the present results.

These observations in conjunction with those of Experiment 1 illuminate the mechanisms underlying excitatory and inhibitory stimulus control in backward conditioning. Our preferred interpretation is that the excitatory and inhibitory potential of a backward $\mathrm{CS}$ are both mediated by the conditioning context. In Experiment 1 , posttraining extinction of the training context attenuated excitatory responding to a backward-trained CS. In the present experiment, we similarly observed an attenuation of inhibitory 


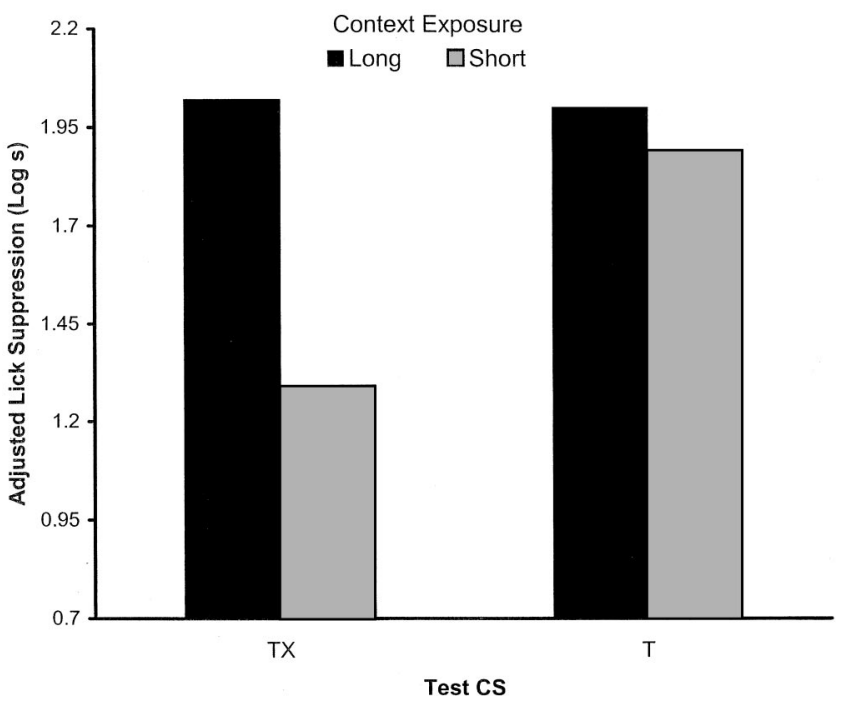

Figure 2. Inhibition test in Experiment 2: adjusted mean drinking suppression during the presentation of CS TX compound and CS T element. The adjustment was based on the pre-CS drinking scores. TX $=$ tone-click compound; $\mathrm{T}=$ tone; $\mathrm{CS}=$ conditioned stimulus.

stimulus control of behavior after posttraining context extinction. One possible account of this is that, with extensive backward conditioning, the CS becomes effective in predicting the safe portion of the intertrial interval that immediately follows it (CS $\rightarrow$ post-CS local context $\rightarrow$ no US), relative to the subsequent component of the intertrial interval (global context $\rightarrow$ US; cf. Moscovitch \& LoLordo, 1968). With massive extinction of the excitatory component of the intertrial interval, expectation of a safety period is degraded because conditioned inhibition is a "slave" process to conditioned excitation (Lysle \& Fowler, 1985; Miller \& Schachtman, 1985).

\section{Experiment 3: Specificity of Context Effects on Backward Excitation and Inhibition}

In Experiments 1 and 2, we observed that posttraining extinction of the training context attenuated the excitatory and inhibitory potentials of a backward-trained CS. However, these studies did not determine whether the effect depended on the extinction of the backward training context as opposed to the extinction of any excitatory context. That is, the attenuation of backward-trained excitation and inhibition as a result of extinction of the training context might have occurred regardless of which excitatory context the subjects in Experiments 1 and 2 had been exposed to during the context extinction phase. In contrast, the context mediation hypothesis predicts a loss of behavioral control by a backward-trained CS only if the context extinguished is that which was used for backward training. Experiment 3 was conducted to determine if the previously observed results were dependent on the training context per se being extinguished during Phase 3.

In addition to addressing the context specificity problem, another change was also made in the present experiment. Instead of training the transfer excitor(s) in the same context in which the target CS had been trained, as was done in Experiments 1 and 2, we trained them in a novel context. This change was implemented to circumvent the possibility that training transfer excitors after context extinction in the extinguished context might have reestablished the context-US association.

Specifically, in Experiment 3 we trained within subjects two backward CSs ( $\mathrm{X}$ and $\mathrm{Y}$ ) in two separate contexts ( $\mathrm{A}$ and $\mathrm{B}$ ), respectively, thereby making both contexts highly excitatory in Phase 1 (see Table 3 ). The few group received 4 US $\rightarrow \mathrm{X}$ and 4 $\mathrm{US} \rightarrow \mathrm{Y}$ backward pairings in Contexts A and B, respectively. The many group received 96 US $\rightarrow \mathrm{X}$ and $96 \mathrm{US} \rightarrow \mathrm{Y}$ backward pairings in Contexts $\mathrm{A}$ and $\mathrm{B}$, respectively. In Phase 2, all subjects received $10 \mathrm{hr}$ of context-alone exposure to Context $\mathrm{A}$, as in Experiments 1 and 2. If the present effects are context specific, this treatment should have extinguished the excitatory value of (global) Context A, thereby degrading the excitatory value of CS X in the few group and the inhibitory value of CS X in the many group but not the excitatory or inhibitory potentials of CS Y. In Phase 3, all subjects received $8 \mathrm{~T} \rightarrow$ US and $8 \mathrm{~S} \rightarrow$ US forward pairings in Context $\mathrm{C}$. This manipulation avoided training of the transfer test excitors in the context that had previously been extinguished. At test, animals in the few group were tested on both CSs X and Y in Context C. If the effects observed previously in Experiment 1 were context specific, these subjects should have suppressed more toward CS Y than CS X because the excitatory value of CS X's training context was devalued relative to CS Y's training context. Animals in the many group were tested on the compounds TX and $\mathrm{SY}$ in Context C. If the effects observed previously in Experiment 2 were context specific, we expected to find that these

Table 3

Design Summary for Experiment 3: Summation and Excitor Tests

\begin{tabular}{|c|c|c|c|c|c|c|}
\hline Group & $\mathrm{Ph}$ & e 1 & Phase 2 & Phase 3 & Tes & \\
\hline $\begin{array}{l}\text { Few } \\
\text { Many }\end{array}$ & $\begin{array}{l}(4 \mathrm{US} \rightarrow \mathrm{X})_{\mathrm{A}} \\
(96 \mathrm{US} \rightarrow \mathrm{X})_{\mathrm{A}}\end{array}$ & $\begin{array}{l}(4 \mathrm{US} \rightarrow \mathrm{Y})_{\mathrm{B}} \\
(96 \mathrm{US} \rightarrow \mathrm{Y})_{\mathrm{B}}\end{array}$ & $\begin{array}{l}(600 \min )_{\mathrm{A}} \\
(600 \min )_{\mathrm{A}}\end{array}$ & $\begin{array}{l}(8 \mathrm{~T} \rightarrow \mathrm{US} / 8 \mathrm{~S} \rightarrow \mathrm{US})_{\mathrm{C}} \\
(8 \mathrm{~T} \rightarrow \mathrm{US} / 8 \mathrm{~S} \rightarrow \mathrm{US})_{\mathrm{C}}\end{array}$ & $\begin{array}{c}\mathrm{X}(\mathrm{cr}) \\
\mathrm{TX}(\mathrm{CR})\end{array}$ & $\begin{array}{l}Y(C R) \\
\text { SY (cr) }\end{array}$ \\
\hline
\end{tabular}

Note. Few and many denote 4 and 96 Phase 1 backward pairings, respectively, of CSs X and Y. Subscript $C$ denotes Context $\mathrm{C}$, and Subscripts $A$ and $B$ denote $\mathrm{V}$ and $\mathrm{R}$ chambers, counterbalanced within groups. Numbers 4, 8, and 96 denote number of trials. $C R$ (conditioned responding) denotes strong responding, and $c r$ denotes weak responding, as anticipated by the context mediation hypothesis. $\mathrm{Y}$ and $\mathrm{X}=$ white noise and click, counterbalanced within groups; $\mathrm{T}$ and $\mathrm{S}=$ tone and buzzer, counterbalanced within groups; US = unconditioned stimulus (1-mA, 1-s duration footshock); $\rightarrow=$ followed by; / = interspersing of trials; TX and SY $=$ compound stimuli of $\mathrm{T}$ and $\mathrm{X}$ and of $\mathrm{S}$ and $\mathrm{Y}$, respectively; $(600 \mathrm{~min})=600-\mathrm{min}$ exposure to Context $\mathrm{A}$ alone; CS = conditioned stimulus. 
subjects would suppress more to CS TX than CS SY because Context A (the context in which CS $\mathrm{X}$ had been trained) was devalued, but Context B was not.

\section{Method}

\section{Subjects}

Twelve experimentally naive male (267-391 g) and 12 female (190-284 g) Sprague-Dawley descended rats bred in our colony served as subjects. Housing and water-deprivation schedules were identical to Experiments 1 and 2. The subjects were randomly assigned to one of two groups ( $n \mathrm{~s}=$ 12): few and many.

\section{Apparatus}

Three types of enclosures were used (R, V, and C). Enclosures R and V served as Contexts A and B, counterbalanced within groups. Enclosure R was a clear, Plexiglas chamber in the shape of a rectangular box, $22.75 \times 8.25 \times 13.0 \mathrm{~cm}(1 \times \mathrm{w} \times \mathrm{h})$, with a floor constructed of 0.48 -cm diameter rods, $1.5 \mathrm{~cm}$ center to center, connected by NE-2 neon bulbs, which allowed constant-current footshock to be delivered by means of a high-voltage AC circuit in series with a 1.0-M $\Omega$ resistor. Each of six copies of Enclosure R has its own environmental isolation chest. Enclosure $\mathrm{R}$ was dimly illuminated by a $2-\mathrm{W}$ (nominal at $120 \mathrm{VAC}$ ) bulb driven at 60 VAC mounted on an inside wall of the environmental isolation chest approximately $30 \mathrm{~cm}$ from the animal enclosure.

Enclosure V was a 25.5-cm long box in the shape of a vertical truncated $\mathrm{V}(28 \mathrm{~cm}$ high, $21 \mathrm{~cm}$ wide at the top, $5.25 \mathrm{~cm}$ wide at the bottom). Each of six copies of Enclosure V has its own environmental isolation chest. The floor and long walls were constructed of stainless steel sheeting, and the end walls were black Plexiglas. The ceiling was clear Plexiglas. The floor consisted of two parallel metal plates, each $2-\mathrm{cm}$ wide with a $1.25-\mathrm{cm}$ gap between them that permitted the administration of constant-current footshock delivered by means of a high-voltage AC circuit in series with a 1.0-M $\Omega$ resistor. Enclosure V was dimly illuminated by a 7-W (nominal at $120 \mathrm{VAC}$ ) bulb driven at $60 \mathrm{VAC}$ mounted on an inside wall of the environmental isolation chest approximately $30 \mathrm{~cm}$ from the animal enclosure, with the light entering the animal enclosure primarily reflected from the roof of the environmental chest. Because of differences in opaqueness of the walls of the two types of enclosures, this level of illumination roughly matched that of Enclosure R. Each instance of Context $\mathrm{A}$ and $\mathrm{B}$ was equipped with two $45-\Omega$ speakers, which were mounted on different interior walls of each sound-attenuating chest. The two speakers could deliver a click-train ( 6 per second) and white noise at $8 \mathrm{~dB}$ (A scale) above the ambient background. Background noise level, primarily from a ventilation fan, was $78 \mathrm{~dB}$ (A scale).

A third context, Context $\mathrm{C}$, was used for training of transfer excitors and testing. Context $\mathrm{C}$ consisted of 12 operant chambers, each measuring 30.5 $\mathrm{cm} \times 27.5 \mathrm{~cm} \times 27.3 \mathrm{~cm}(1 \times \mathrm{w} \times \mathrm{h})$. All chambers had clear Plexiglas ceilings and side walls as well as metal front and back walls. Chamber floors were 4-mm grids spaced $1.7 \mathrm{~cm}$ apart center to center, connected with NE-2 neon bulbs, which allowed constant-current footshock to be delivered by means of a high-voltage $\mathrm{AC}$ circuit in series with a 1.0-M $\Omega$ resistor. To further distinguish Context $\mathrm{C}$ from Contexts $\mathrm{A}$ and $\mathrm{B}$, an odor was added to Context $\mathrm{C}$, and no houselight was present. The odor cue (mint) was produced as in Experiments 1 and 2. Each instance of Context $\mathrm{C}$ was housed in its own sound- and light-attenuating cubicle. Each instance of Context $\mathrm{C}$ could be equipped with a water-filled lick tube, which when installed, extended $1 \mathrm{~cm}$ from the rear of a cylindrical niche (axis perpendicular to a chamber wall) $4.5 \mathrm{~cm}$ in diameter, left-right centered with its bottom $1.75 \mathrm{~cm}$ above the floor of the apparatus, and $5.0-\mathrm{cm}$ deep. There was a photobeam detector $1 \mathrm{~cm}$ in front of the lick tube, which served as a means of measuring the duration of drinking bouts.
Three $45-\Omega$ speakers mounted on different interior walls of each soundattenuating chest and a buzzer located at the interior left wall of the animal enclosures could deliver a complex tone (consisting of $3000-\mathrm{Hz}$ and $3200-\mathrm{Hz}$ pure tones), a click-train (6 per second), a white noise, and a buzzing sound, respectively, at $8 \mathrm{~dB}$ (A scale) above the ambient background sound of $78 \mathrm{~dB}$ that was produced primarily by a ventilation fan. The tone and buzzing sound served as CSs T and S, counterbalanced within groups, and the click-train and white noise served as CSs $\mathrm{X}$ and $\mathrm{Y}$, counterbalanced within groups.

As in Experiments 1 and 2, the duration of all stimuli (X, Y, S, and T) during training was $30 \mathrm{~s}$, and the US was a 1.0-mA, 1-s footshock. The water-filled tubes were only inserted in Context $\mathrm{C}$ during acclimation, reacclimation, and testing phases but were taken out during transfer excitor training (Phase 3) to avoid the possibility of animals drinking when shock was delivered.

\section{Procedure}

Table 3 summarizes the critical aspects of Experiment 3. The procedures were identical to Experiments 1 and 2 unless stated otherwise.

Acclimation. On Day 1, animals in the many group were acclimated to Context $\mathrm{C}$ for $30 \mathrm{~min}$ on Day 1, whereas animals in the few group were acclimated to Context $\mathrm{C}$ for $30 \mathrm{~min}$ on Day 12. In this phase, no nominal stimuli were programmed to occur, and the animals had free access to the water-filled tubes, as in Experiments 1 and 2.

Backward conditioning (Phase 1). On Days 2-13, subjects in the many group experienced 8 daily backward pairings of US $\rightarrow \mathrm{X}$ in Context $\mathrm{A}$ and 8 daily pairings of US $\rightarrow \mathrm{Y}$ in Context $\mathrm{B}$. Each session was $30 \mathrm{~min}$ in length. Mean intertrial intervals for each trial type and trial-free periods were identical to the many condition in Experiments 1 and 2. As in the many condition of Experiments 1 and 2, two training schedules were alternated. Animals in the few group were handled twice daily during the Day 1-11 waiting period to equate the handling of the two groups. On Day 13, the few group experienced 4 US $\rightarrow \mathrm{X}$ backward pairings in Context A and 4 US $\rightarrow$ Y backward pairings in Context B. Each session was $20 \mathrm{~min}$ in length. Mean intertrial interval and empty trial periods were identical to the few condition in Experiment 1. Because each subject of both groups experienced US $\rightarrow \mathrm{X}$ and US $\rightarrow \mathrm{Y}$ pairings in Contexts $\mathrm{A}$ and $\mathrm{B}$, respectively, on each day, the order of training in Contexts A and B were counterbalanced within groups. Half of each group experienced Context A training before Context $\mathrm{B}$ training on odd numbered days and Context $\mathrm{B}$ training before Context A training on even numbered days. This was reversed for the other half of the animals. The two sessions were separated by approximately $3 \mathrm{hr}$.

Context extinction (Phase 2). On Days 14-17, all subjects underwent context extinction in Context A. During this phase, the subjects were placed in Context A without presentation of any nominal stimulus. Each subject received 150-min context-alone exposure for 4 sessions, for a total of $10 \mathrm{hr}$ of exposure.

Transfer excitor training (Phase 3). On Days 18 and 19, all subjects experienced interspersed $4 \mathrm{~T} \rightarrow$ US trials and $4 \mathrm{~S} \rightarrow$ US trials in Context C. As in Experiments 1 and 2, session duration was $16 \mathrm{~min}$, and the mean intertrial interval for this phase was $125 \mathrm{~s}$ (values 105, 120, and $150 \mathrm{~s}$ ). The patterns of stimulus presentations were the following. On Day 18, the trial presentations were $\mathrm{T}+, \mathrm{S}+, \mathrm{S}+, \mathrm{T}+, \mathrm{S}+, \mathrm{T}+, \mathrm{T}+, \mathrm{S}+$, and on Day 19, the trial presentations were $\mathrm{S}+, \mathrm{T}+, \mathrm{T}+, \mathrm{S}+, \mathrm{T}+, \mathrm{S}+, \mathrm{S}+, \mathrm{T}+$. The first $4 \mathrm{~min}$ and the last $3.5 \mathrm{~min}$ within each session were free of nominal stimuli.

Reacclimation and testing. On Days 20 and 21, reacclimation took place in Context C. As in Experiments 1 and 2, during this phase no nominal stimuli were programmed to occur, and the animals had free access to the water-filled tubes. On Days 22 and 23, the few group was tested on CSs X and Y, whereas the many group was tested on compound $\mathrm{TX}$ and SY. No tests were conducted with CSs $\mathrm{S}$ or $\mathrm{T}$ alone because 
training with these stimuli was identical to that of CS T in Experiment 2, which demonstrated that such training produced strong excitation. All testing occurred in Context C. For each animal, only one stimulus or compound was tested per day, with the order of testing the two stimuli or two compounds counterbalanced across days within each group. The testing procedures, the subject exclusion criterion, and the test ceiling were identical to Experiment 2. On the basis of the subject exclusion criterion established in Experiments 1 and 2 (completion of the first 5 cumulative seconds of drinking within $60 \mathrm{~s}$ of the start of the session), 2 subjects from the few group and 2 from the many group were excluded from the analyses. Moreover, the data from 2 more subjects in the few group were also discarded from the analyses as a result of illness and an equipment failure. These subjects were uniformly distributed across the counterbalancing of test order. On Test 1 (Day 22), the target stimulus was presented for a full $15 \mathrm{~min}$ to equate exposure to the target stimulus across subjects, thereby minimizing differential influence of experience of Test 1 on Test 2 performance. As in Experiments 1 and 2, all of the drinking scores (both pre-CS and during CS presentation) were converted into $\log _{10}$ times to better approximate the normality assumption of parametric statistical tests.

\section{Results and Discussion}

The present experiment replicated the data patterns of Experiments 1 and 2. That is, extinction of the conditioning context attenuated the excitatory potential of CS X relative to CS Y in the few group and marginally attenuated the inhibitory potential of CS $\mathrm{X}$ relative to CS $\mathrm{Y}$ in the many group (see Figure 3 ). Thus, context specificity was demonstrated in the case of a backward-trained conditioned excitor and was suggested in the case of a backwardtrained inhibitor.

The following statistical analyses confirmed these conclusions. Because of the design of the experiment, only comparisons within groups were of interest. Essentially, Experiment 3 was really two independent experiments, the few group constituting one experi-

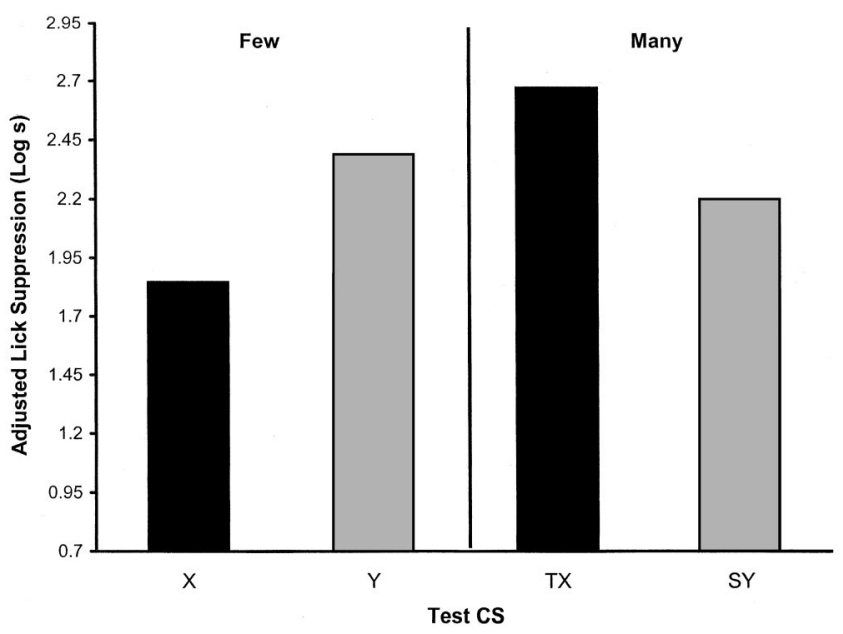

Figure 3. Inhibition and excitor tests in Experiment 3: adjusted mean drinking suppression during the presentation of test CSs (X, Y, TX, and $\mathrm{SY}$ ). The adjustment was based on the pre-CS drinking scores. The black bars depict test CSs X and TX from the extinguished context (A), whereas the gray bars depict test CSs Y and SY from the nonextinguished context (B). The left-hand columns indicate means from the few group, whereas the right-hand columns indicate means from the many group. $\mathrm{X}$ and $\mathrm{Y}=$ clicks and white noise, counterbalanced within groups; $\mathrm{T}$ and $\mathrm{S}=$ tone and buzzer, counterbalanced within groups; CS = conditioned stimulus. ment and the many group constituting the other. Consequently, no between-groups comparisons were conducted. Separate ANOVAs of pre-CS scores from the few group and from the many group for each of the 2 test days found no significant effects of test order, test stimulus, or an interaction of these two factors (all $p \mathrm{~s}>.10$ ). ANOVAs rather than ANCOVAs were used to examine the CS scores because the appropriateness of ANCOVAs was questionable because of each subject having a different pre-CS score for each of its two CS scores (i.e., $\mathrm{X}$ and $\mathrm{Y}$ ).

A $2 \times 2$ (test stimulus [X vs. Y] and test order [X first vs. last]) ANOVA of the CS scores from the few group found a main effect of stimulus (X vs. Y, within subject), $F(1,6)=7.56, M S E=0.15$, $p<.05$, and test order (X tested first vs. second, between subject), $F(1,6)=10.42, M S E=0.15, p<.05$, but no Stimulus $\times$ Test Day interaction, $F(1,6)<1.0$. The effect of test day arose from a general reduction in suppression going from the first to the second test day. Presumably this was a result of generalization of extinction across test days and was not relevant to our central concern. More important, the stimulus effect arose from suppression to CS $\mathrm{X}$ being less than that to CS Y, presumably as a result of extinction of the context used from training CS X. This effect of posttraining context extinction on CS $\mathrm{X}$ replicates what was observed in Experiment 1 and demonstrates that it is context specific. Moreover, there is no basis here to wonder why training of the transfer excitors did not reinstate the excitatory status of the contexts used for backward training because transfer excitor training occurred in a different context than did target training.

For the many group, an ANOVA of the CS scores with stimulus (TX vs. SY) and test order (TX tested first vs. second) as factors found a marginally significant main effect of stimulus, $F(1$, $8)=4.53, M S E=0.22, p<.08$, but no main effect of test day and no Test $\mathrm{CS} \times$ Test Day interaction, $F_{\mathrm{S}}(1,8)<1$. Although we failed to achieve significance here with a two-tailed alpha value of .05 , the prediction of the context mediation hypothesis as well as the results of Experiment 2 lend credence to the use of a one-tailed test here, for which $F(1,8)=4.53$ is significant at an alpha value of .05. It is important to note that the marginal difference in suppression between CS X and CS Y observed here arose from less suppression to SY than TX, presumably because extinction of the training context used for conditioning CS X had reduced the inhibitory potential of CS X. This effect of extinction of the training context on CS X is congruent with what was observed in Experiment 2 and suggests that it is context specific.

Overall, Experiment 3 provided confirmation of the results obtained in Experiments 1 and 2. That is, extinction of the associative status of the context used for backward conditioning attenuated both excitatory and inhibitory potentials of the target stimuli. Presumably, during extinction of Context A in the few group, the global Context $\mathrm{A} \rightarrow$ US association, which was formed as a result of few backward US $\rightarrow \mathrm{X}$ pairings that occurred there during Phase 1, was extinguished. This seemingly attenuated the CS X's potential to activate the representation of the US using mediation by Context A. Similarly, for the many group, in which CSs X and $\mathrm{Y}$ became inhibitory as a result of extensive backward US $\rightarrow \mathrm{CS}$ pairings in Phase 1, extinction of Context A reduced the inhibitory potential of CS X. This occurred as a result of devaluation of the excitatory associative value of global Context A, which presumably supported the inhibitory potential of the local context that was present immediately after presentation of the CS. In addition to 
replicating the observations of Experiments 1 and 2, the present experiment provides evidence that the attenuation of excitatory and inhibitory backward conditioning after the extinction of the conditioning context was specific to the target context. That is, the attenuation of excitation and inhibition found in Experiments 1 and 2 was not a result of mere extinction of any irrelevant or nontarget context, but instead, it occurred only when the context extinguished was that in which the target cue had been trained.

\section{General Discussion}

The occurrence of backward conditioning has posed a problem to the basic underlying assumption of many contemporary learning models. Most of the prevailing models implicitly assume that learning only occurs in predictive situations (e.g., Mackintosh, 1975; Pearce \& Hall, 1980; Rescorla \& Wagner, 1972; but see Wagner, 1981). We prefer to view associative acquisition as a function of contiguity alone (rather than predictive value) and view retrieval and conditioned responding as a function of predictive value. The present experiments illuminate the nature and the mechanisms of stimulus control of behavior following backward conditioning trials. Notably, the present context-mediation account of both excitatory and inhibitory stimulus control resulting from US $\rightarrow$ CS pairings are couched exclusively in terms of predictive associations, thereby obviating the learning-performance dispute in this situation. That is, we suggest that both excitation and inhibition after backward conditioning arises from the CS predicting the context that immediately follows it. Backward associations (i.e., US $\leftarrow$ CS) may also be formed during backward conditioning, but they are ordinarily behaviorally silent (see Savastano \& Miller, 1998, for discussion).

Consistent with the context-mediation hypothesis, we found in Experiment 1 that posttraining extinction of the training context reduced the excitatory value of a backward-trained CS that had been paired with a US only a few times. This observation is consistent with the excitatory potential of a backward-trained CS arising conjointly from CS-context and context-US associations. Moreover, it is inconsistent with the view that backward-trained CSs become excitatory because they are associated to the US that initiates the subsequent backward trial. If that were the case, context extinction should have no effect on the CS's excitatory value.

Also consistent with the context-mediation hypothesis, in Experiment 2 we found using a summation test that posttraining context extinction attenuated conditioned inhibition that had been produced through many backward pairings. Specifically, posttraining extinction of the conditioning context attenuated the potential of the backward-trained CS X to counteract suppression of drinking by the independently trained transfer excitor, T. Thus, the excitatory status of the global context now seemed to be necessary to maintain the CS's inhibitory potential. That is, the CS was more inhibitory when the global context-US excitatory association was left intact. Presumably, the inhibitory value of the local context was dependent on the excitatory value of the global context, which is consistent with inhibition being a slave process (Lysle \& Fowler, 1985).

Experiment 3 provided further support for the results obtained in Experiments 1 and 2, while controlling for context specificity. Specifically, Experiment 3 found that posttraining extinction of
Context A in the few group attenuated the excitatory potential of the backward-trained CS, which had been trained in Context A (CS $\mathrm{X}$ ), whereas the same context manipulation did not attenuate the excitation of the other backward-trained CS, which was trained in Context B (CS Y). Similarly, posttraining extinction of Context A in the many group tended to attenuate the inhibitory status of the backward-trained CS, which had been trained in Context A (CS X), more so than the inhibitory status of the backward-trained CS, which had been trained in Context B (CS Y). Moreover, in Experiment 3 the training of the transfer excitors ( $\mathrm{S}$ and $\mathrm{T}$ ) occurred outside of the contexts used for backward conditioning and subsequent context extinction, minimizing any possible consequence of this training on the associative status of the backward conditioning contexts.

According to the context-mediation account, the global training context in a backward conditioning paradigm becomes highly excitatory as a result of the unsignaled USs. With few backward pairings, the local context immediately following the CS is not differentiated from the global context. Consequently, the CS predicts this excitatory context, making the CS a second-order conditioned excitor. In contrast, with many backward pairings, the CS comes to predict the local context that immediately follows it, which is safe (i.e., inhibitory) relative to the excitatory global context. Seemingly, the backward-trained CS became a signal for this inhibitory local context. Thus, posttraining extinction of the global context degrades both the excitation that it mediates in the case of few backward trials and the inhibitory status of the local context that it supports in the case of many backward trials (e.g., Lysle \& Fowler, 1985).

The assumption of a representation of a safe local context coexisting with the representation of an excitatory global context (after many backward pairings) in the present account of backward conditioned inhibition is similar in some respects to Mowrer's (1960) two-factor theory of avoidance learning, Solomon's (1980; Solomon \& Corbit, 1974) opponent-process theory, and particularly Denny's (1971) relaxation theory. These theories all assumed that reduction of fear to a cue is due to a development of a positive affect following each aversive event after sufficient trials, without the loss of the original fear. In Mowrer's two-factor theory, fear reduction is a result of escape from a fear-inducing cue. The fear-inducing cue retains its aversive qualities just as we propose the global context does. In Solomon's opponent-process theory, fear reduction is due to the development of a fear-opposing (B) process, with the fear-recruiting (A) process maintaining its strength. In the terminology of the context-mediation hypothesis, it is as if the CS becomes a signal for the B process. Denny's relaxation theory assumes that immediately following a trial, absence of aversive stimulation in the fear-inducing environment conditions a relaxation response (relief), such that net fear is reduced without loss of the basis of fear. Seemingly, the contextmediation hypothesis with its notion of an inhibitory local context is similar to these earlier models. However, unlike these other models, which were designed to address situations with discrete fear-inducing CSs, the context-mediation hypothesis anticipates that posttraining extinction of the context will reduce inhibition.

According to the context-mediation hypothesis, inhibitory backward conditioning is a consequence of the CS, over many backward pairings with the US, coming to predict a shock-free local context in juxtaposition with the subsequent global context, which 
is more excitatory. Nonreinforced exposures to the CS in the absence of USs following extensive backward conditioning should strengthen the association between the CS and the post-CS US-free local context but weaken the association between the local context and fear-inducing global context. Hence, the context-mediation hypothesis does not make a strong prediction in this case but is not challenged by Williams and Overmier's (1988) observation that a backward-trained CS becomes more inhibitory as a result of extinction of the CS.

Consistent with the view that safety is timed in inhibitory backward conditioning, Dostalek and Krasa (1972, 1973), using eyelid conditioning, found that, when truly random intertrial intervals were used during training, a backward CS acquired and retained excitatory potential after even hundreds of backward pairings. Because the intertrial intervals were truly random, the excitation of the extensively trained backward CS could have been due to simple pseudoconditioning. However, Dostalek and Krasa (1973) observed that groups trained with backward and forward trials reached asymptotes of excitatory responding, whereas a pseudoconditioning control group did not. When the intertrial intervals are truly random, a subject is not able to encode temporal locations of the USs relative to preceding trials. Thus, the lack of asymptotic conditioned inhibition seen in this situation is consistent with the context-mediation view.

The context-mediation account of excitatory backward conditioning assumes that after a few backward pairings, the backwardtrained CS signals the onset of an excitatory global context, thereby allowing the CS to elicit an excitatory conditioned response through second-order conditioning. This interpretation predicts that, under favorable circumstances (i.e., few trials and a highly excitatory global context), an explicitly unpaired CS (unpaired presentations of a CS and US) should be capable of eliciting an excitatory conditioned response. That is, if excitation of a backward-trained excitor is mediated by the conditioning context, one should expect that excitation of an explicitly unpaired CS to also be mediated by the conditioning context. This somewhat counterintuitive prediction has little supporting evidence and may in fact ultimately stand as evidence against the context mediation hypothesis. The present series of experiments did not examine this prediction because the present focus was on backward conditioning. However, several published studies have suggested that an explicitly unpaired CS can acquire excitation early in training and that this excitatory potential is susceptible to manipulations that seemingly modify the associative status of the conditioning context (e.g., Albert \& Ayres, 1997; Droungas \& LoLordo, 1994; Gordon, McGinnis, \& Weaver, 1985; cf. Spetch et al., 1982). For instance, Droungas and LoLordo found that an explicitly unpaired CS could serve as a functional excitor when the intertrial intervals during training were short $(55 \mathrm{~s})$ but not long (410 s; see also Spetch et al., 1982). These studies suggest that in order for an explicitly unpaired CS to gain excitation, the intertrial intervals (CS-US and US-US onset times) have to be short. Whether this dependence on intertrial interval reflects long intertrial intervals weakening the excitatory status of the context (consistent with the context-mediation hypothesis) or long intertrial intervals weakening direct associations between the CS and US (less consistent with the context-mediation hypothesis) is not clear at this time.

Excitatory and inhibitory effects of backward conditioning are also readily explained by some more complex learning models, such as Wagner's (1981) SOP theory. In the framework of SOP, during the initial US $\rightarrow$ CS pairings, portions of the US, CS, and context representational elements are simultaneously activated into a high-activation (A1) state. In Wagner's model, simultaneous activation of elements in the A1 state is assumed to produce an excitatory association between the elements. Thus, excitatory backward conditioning is anticipated as the result of a direct association between the CS and the representation of the US that immediately preceded it. However, at the same time a context-US association is being formed. With further training trials, the excitatory context-US association now allows the context to activate the US elements into a lower activation (A2) state, so that when the $\mathrm{CS}$ is presented and activated into the A1 state, the US representation is already activated in the A2 state. When this happens, a CS-US inhibitory association develops because inhibition is hypothesized to result when CS elements are activated in the A1 state and US elements are activated in the A2 state. Thus, with sufficient trials, the backward CS might be expected to become an inhibitor. However, unlike the contextual-mediation account, SOP is unable to account for the reduction, as a consequence of posttraining extinction of the training context, in excitation after few backward pairings and in inhibition after many backward pairings.

The present series provides data for backward inhibitory conditioning analogous to studies of conditioned inhibition produced through other procedures. For example, during Pavlovian conditioned inhibition treatment, a CS (A) is reinforced with a US when it is presented alone but is not reinforced when it is presented in compound with a target CS (X), with these two trial types being interspersed ( $\rightarrow$ US/AX - ). When CS X is later presented in compound with a transfer excitor B within a summation test, the $\mathrm{BX}$ compound evokes weaker responding than when $\mathrm{B}$ is presented alone. Yin, Barnet, and Miller (1994) found that with few $\mathrm{AX}$ - trials, CS X came to act as a second-order excitor. However, with more $\mathrm{AX}$ - trials, while holding the number of $\mathrm{A} \rightarrow \mathrm{US}$ trials constant, CS X came to act as a conditioned inhibitor. The shift of response potential from excitation to inhibition seen in Pavlovian conditioned inhibition is similar to the shift of response potential observed in backward conditioning (e.g., Cole \& Miller, 1999; Heth, 1976). Despite this similarity, it is unclear at this time if a common mechanism is responsible.

The present experiments are seemingly inconsistent with the conclusion of Williams and Hurlburt (2000) that forward and backward excitatory CSs have the same associative structures, even though they differ in temporal arrangement of CS presentation relative to the US. However, their data were from procedures quite different from ours. In the present Experiment 1, massive posttraining context exposure degraded the excitatory value of the backward-trained CS X when CS X was an excitatory stimulus. In contrast, other research has shown that posttraining context extinction has either no effect or an opposite effect on a forwardtrained CS (e.g., Grahame, Barnet, \& Miller, 1992). Specifically, if context extinction has any effect at all on responding to a forwardpaired cue (i.e., CS $\rightarrow$ US), it increases conditioned responding. Although the present experiments appear inconsistent with Williams and Hurlburt's conclusions, we did not include a forwardtraining condition (CS $\rightarrow$ US), which could be directly compared with the present backward conditioning groups. Therefore, we must qualify our conclusions here concerning Williams and Hurlburt's assertion. 
In summary, the present experiments provide empirical support for a higher order conditioning interpretation (the contextmediation account) of both excitatory and inhibitory backward conditioning. The present data suggest that the conditioning context is a critical mediator for both the excitatory and the inhibitory status of a backward-trained CS.

\section{References}

Albert, M., \& Ayres, J. J. B. (1997). One-trial simultaneous and backward excitatory fear conditioning in rats: Lick suppression, freezing, and rearing to CS compounds and their elements. Animal Learning \& Behavior, 25, 210-220.

Ayres, J. J. B., Haddad, C., \& Albert, M. (1987). One-trial excitatory backward conditioning as assessed by conditioned suppression of licking in rats: Concurrent observations of lick suppression and defensive behaviors. Animal Learning \& Behavior, 15, 212-217.

Barnet, R. C., \& Miller, R. R. (1996). Second-order excitation mediated by a backward conditioned inhibitor. Journal of Experimental Psychology: Animal Behavior Processes, 22, 279-296.

Best, M. R., Dunn, D. P., Batson, J. D., Meachum, C. L., \& Nash, S. M. (1985). Extinguishing conditioned inhibition in flavour-aversion learning: Effects of repeated testing and extinction of the excitatory element. Quarterly Journal of Experimental Psychology, 37B, 359-378.

Cole, R. P., \& Miller. R. R. (1999). Conditioned excitation and conditioned inhibition acquired through backward conditioning. Learning and Motivation, 30, 129-156.

Denny, M. R. (1971). Relaxation theory and experiments. In R. Brush (Ed.), Aversive conditioning and learning (pp. 235-295). New York: Academic Press.

Dostalek, C., \& Krasa, H. (1972). Backward conditioning: One-session vs. ten-session-experiment. Activa Nervosa, 14(Suppl.), 58-59.

Dostalek, C., \& Krasa, H. (1973). The role of unconditioned stimulus intensity in backward conditioning. Activa Nervosa, 15(Suppl.), 239240.

Droungas, A., \& LoLordo, V. M. (1994). Evidence for simultaneous excitatory and inhibitory associations in the explicitly unpaired procedures. Learning and Motivation, 25, 1-25.

Gallistel, C. R., \& Gibbon, J. (2000). Time, rate, and conditioning. Psychological Review, 107, 289-344.

Gibbon, J. (1977). Scalar expectancy theory and Weber's law in animal timing. Psychological Review, 84, 279-325.

Gibbon, J., \& Balsam, P. (1981). Spreading association in time. In C. M. Locurto, H. S. Terrace, \& J. Gibbon (Eds.), Autoshaping and conditioning theory (pp. 219-253). New York: Academic Press.

Gordon, W. C., McGinnis, G. M., \& Weaver, M. S. (1985). The effect of cuing after backward conditioning trials. Learning and Motivation, 16, $444-463$.

Grahame, N. J., Barnet, R. C., \& Miller, R. R. (1992). Pavlovian conditioning in multiple contexts: Competition between contexts for comparator status. Animal Learning \& Behavior, 20, 329-338.

Hallam, S. C., Matzel, L. D., Sloat, J. S., \& Miller, R. R. (1990). Excitation and inhibition as a function of posttraining extinction of the excitatory cue used in Pavlovian inhibition training. Learning and Motivation, 21, $59-84$.

Heth, D. C. (1976). Simultaneous and backward fear conditioning as a function of number of CS-UCS pairings. Journal of Experimental Psychology: Animal Behavior Processes, 2, 117-129.

Heth, D. C., \& Rescorla, R. A. (1973). Simultaneous and backward fear conditioning in the rat. Journal of Comparative and Physiological Psychology, 82, 434-443.

Holland, P. C., \& Forbes, D. T. (1982). Representation-mediated extinction of conditioned flavor aversions. Learning and Motivation, 13, 454-471.

Kasprow, W. J., Schachtman, T. R., \& Miller, R. R. (1987). The compar- ator hypothesis of conditioned response generation: Manifest conditioned excitation and inhibition as a function of relative excitation strengths of CS and conditioning context at the time of testing. Journal of Experimental Psychology: Animal Behavior Processes, 13, 395-406.

Keith-Lucas, T., \& Guttman, N. (1975). Robust-single-trial delayed backward conditioning. Journal of Comparative and Physiological Psychology, 88, 468-476.

LoLordo, V. M., \& Fairless, J. L. (1985). Pavlovian conditioned inhibition: The literature since 1969. In R. R. Miller \& N. E. Spear (Eds.), Information processing in animals: Conditioned inhibition (pp. 1-49). Hillsdale, NJ: Erlbaum.

Lysle, D. T., \& Fowler, H. (1985). Inhibition as a "slave" process: Deactivation of conditioned inhibition through extinction of conditioned excitation. Journal of Experimental Psychology: Animal Behavior Processes, 11, 71-94.

Mackintosh, N. J. (1975). A theory of attention: Variations in the associability of stimuli with reinforcement. Psychological Review, 82, 276298.

Maier, S. F., Rapaport, P., \& Wheatley, K. (1976). Conditioned inhibition and the UCS-CS interval. Animal Learning \& Behavior, 4, 217-220.

Marlin, N. A. (1983). Second-order conditioning using a contextual stimulus as S1. Animal Learning \& Behavior, 11, 290-294.

McNish, K. A., Betts, S. L., Brandon, S. E., \& Wagner, A. R. (1997). Divergence of conditioned eyeblink and conditioned fear in backward Pavlovian training. Animal Learning \& Behavior, 25, 43-52.

Miller, R. R., \& Barnet, R. B. (1993). The role of time in elementary associations. Current Directions in Psychological Science, 2, 106-111.

Miller, R. R., Hallam, S. C., Hong, J. Y., \& Dufore, D. S. (1991). Associative structure of differential inhibition: Implications for models of conditioned inhibition. Journal of Experimental Psychology: Animal Behavior Processes, 17, 141-150.

Miller, R. R., \& Schachtman, T. R. (1985). Conditioned context as an associative baseline: Implications for response generation and the nature of conditioned inhibition. In R. R. Miller \& N. E. Spear (Eds.), Information processing in animals: Conditioned inhibition (pp. 51-87). Hillsdale, NJ: Erlbaum.

Moscovitch, A., \& LoLordo, V. M. (1968). Role of safety in the Pavlovian backward fear conditioning procedure. Journal of Comparative and Physiological Psychology, 66, 673-678.

Mowrer, H. O. (1960). Learning theory and behavior. New York: Wiley.

Papini, M. R., \& Bitterman, M. E. (1993). The two-test strategy in the study of inhibitory conditioning. Journal of Experimental Psychology: Animal Behavior Processes, 19, 342-352.

Pearce, J. M., \& Hall, G. (1980). A model for Pavlovian learning: Variations in the effectiveness of conditioned but not of unconditioned stimuli. Psychological Review, 87, 532-552.

Plotkin, H. C., \& Oakley, D. A. (1975). Backward conditioning in the rabbit (Oryctolagus cunniculus). Journal of Comparative and Physiological Psychology, 88, 586-590.

Rescorla, R. A. (1982). Simultaneous second-order conditioning produces S-S learning in conditioned suppression. Journal of Experimental Psychology: Animal Behavior Processes, 8, 23-32.

Rescorla, R. A., \& Wagner, A. R. (1972). A theory of Pavlovian conditioning: Variations in the effectiveness of reinforcement and nonreinforcement. In A. Black \& W. F. Prokasy (Eds.), Classical conditioning: II (pp. 64-99). New York: Appleton-Century-Crofts.

Rizley, R. C., \& Rescorla, R. A. (1972). Associations in second-order conditioning and sensory preconditioning. Journal of Comparative and Physiological Psychology, 81, 1-11.

Savastano, H. I., \& Miller, R. R. (1998). Time as content in Pavlovian conditioning. Behavioural Processes, 44, 147-162.

Schachtman, T. R., Brown, A. M., Gordon, E. L., Catterson, D. A., \& Miller, R. R. (1987). Mechanisms underlying retarded emergence of conditioned responding following inhibition training: Evidence for the 
comparator hypothesis. Journal of Experimental Psychology: Animal Behavior Processes, 13, 310-322.

Siegel, S., \& Domjan, M. (1971). Backward conditioning as an inhibitory procedure. Learning and Motivation, 2, 1-11.

Siegel, S., \& Domjan, M. (1974). The inhibitory effect of backward conditioning as a function of the number of backward pairings. Bulletin of the Psychonomic Society, 4, 122-124.

Solomon, R. L. (1980). The opponent-process theory of acquired motivation. American Psychologist, 35, 691-712.

Solomon, R. L., \& Corbit, J. D. (1974). An opponent-process theory of motivation: I. Temporal dynamics of affect. Psychological Review, 81, 119-145.

Spetch, M. L., Terlecki, L. J., Pinel, J. P. J., Wilkie, D. M., \& Treit, D. (1982). Excitatory backward conditioning of defensive burying in rats. Bulletin of the Psychonomic Society, 19, 111-114.

Spetch, M. L., Wilkie, D. M., \& Pinel, J. P. J. (1981). Backward conditioning: A reevaluation of the empirical evidence. Psychological Bulletin, 89, 163-175.

Tait, R. W., \& Saladin, M. E. (1986). Concurrent development of excitatory and inhibitory associations during backward conditioning. Animal Learning \& Behavior, 14, 133-137.

Wagner, A. R. (1981). SOP: A model of automatic memory processing in animal behavior. In N. E. Spear \& R. R. Miller (Eds.), Information processing in animals: Memory mechanisms (pp. 5-47). Hillsdale, NJ: Erlbaum.

Williams, D. A., Dyck, D. C., \& Tait, R. W. (1988). Excitatory backward conditioning in conditioned punishment and conditioned suppression in rats. American Journal of Psychology, 99, 367-384.

Williams, D. A., \& Hurlburt, J. L. (2000). Mechanisms of second-order conditioning with a backward conditioned stimulus. Journal of Experimental Psychology: Animal Behavior Processes, 26, 340-351.

Williams, D. A., \& Overmier, J. B. (1988). Some types of conditioned inhibitors carry collateral excitatory associations. Learning and Motivation, 19, 345-368.

Yin, H., Barnet, R. C., \& Miller, R. R. (1994). Second-order conditioning and Pavlovian conditioned inhibition: Operational similarities and differences. Journal of Experimental Psychology: Animal Behavior Processes, 20, 419-428.

Received December 2, 2002

Revision received January 21, 2003

Accepted January 22, 2003

\section{American Psychological Association SUBSCRIPTION Claims INFORMATION}

Today's Date:

We provide this form to assist members, institutions, and nonmember individuals with any subscription problems. With the appropriate information we can begin a resolution. If you use the services of an agent, please do NOT duplicate claims through them and directly to us. PLEASE PRINT CLEARLY AND IN INK IF POSSIBLE.

\begin{tabular}{lll}
\hline PRINT FULL NAME OR KEY NAME OF DNSTTTUTION & \\
\hline ADDRESS & & \\
\hline CITY & & \\
\hline
\end{tabular}

YOUR NAME AND PHONE NUMBER

TITLE

\section{MEMBER OR CUSTOMER NUMBER (MAY BEFOUNDONANY PASTISSUE LABEL)} DATE YOUR ORDER WAS MAIIED (OR PHONED)

_PREPAID

(If possible, send a copy, front and back, of your cancelled check to help us in our research of your claim.

ISSUES: _ MISSING _ DAMAGED

VOLUME OR YEAR NUMBER OR MONTH

Thank you. Once a claim is received and resolved, delivery of replacement issues routinely takes 4-6 weeks.

(TO BE FILLED OUT BY APA STAFF)

DATE RECEIVED:

ACTION TAKEN:

STAFF NAME:
DATE OF ACTION:

INV. NO. \& DATE:

LABEL NO. \& DATE:

Send this form to APA Subscription Claims, 750 First Street, NE, Washington, DC 20002-4242

PLEASE DO NOT REMOVE. A PHOTOCOPY MAY BE USED. 